Published in Public Health Ethics 2(2)

\title{
Liberalism, Altruism and Group Consent
}

\begin{abstract}
Kalle Grill
ABSTRACT. This article first describes a dilemma for liberalism: On the one hand restricting their own options is an important means for groups of people to shape their lives. On the other hand, group members are typically divided over whether or not to accept option-restricting solutions or policies. Should we restrict the options of all members of a group even though some consent and some do not? This dilemma is particularly relevant to public health policy, which typically target groups of people with no possibility for individuals to opt out. The article then goes on to propose and discuss a series of aggregation rules for individual into group consent. Consideration of a number of scenarios shows that such rules cannot be formulated only in terms of fractions of consenters and non-consenters, but must incorporate their motives and how much they stand to win or lose. This raises further questions, including what is the appropriate impact of altruistic consenters and non-consenters, what should be the impact of costs and benefits and whether these should be understood as gross or net. All these issues are dealt with in a liberal, anti-paternalistic spirit, in order to explore whether group consent can contribute to the justification of optionrestricting public health policy.
\end{abstract}

\section{INTRODUCTION}

According to standard liberal political theory, an action or a policy that restricts the options of a competent person stands in need of justification. One source of such justification is the consent of the person whose options are restricted. Public health measures often restrict the options of competent people. It would seem an important task for liberal political theory to investigate whether such measures can be justified by the consent of those affected. In contrast to medical care, public health measures normally target groups, with no possibility for group members to opt out. Most often, some members consent or would consent, while other members do or would not. A central part of the task, therefore, is to explore how various distributions of consenters and non-consenters within a group can justify restricting the options of the whole group. Such exploration is the aim of this article. 
My conclusion is that aggregation rules for individual into group consent must consider the motives of (non-)consenters - typically self-interested or altruistic, as well as the costs and benefits to them. Such rules will therefore be rather complex. Attention to costs and benefits does not imply outright consequentialism and certainly not costbenefit analysis in simplistic monetary terms. There are aggregation rules that consider both the fraction of consenters versus non-consenters, with different motives, and the distribution of costs and benefits. I propose that such rules are the closest we can get to a classically liberal justification of option-restricting policies by group consent.

This conclusion is hedged with assumptions. The central assumption we may call the group consent assumption, being that groups can morally be treated as if they had consented, even if some members do not consent. As we will see, this assumption is shared by many liberals, though not by strict libertarians who would not accept nonvoluntary restriction for any benefit. I assume that liberalism implies individualism and so that talk of group consent is only metaphorical. Group consent is therefore used here as a normative notion, with no claim to metaphysical or linguistic accuracy. I will also assume that justification of a policy by consent does not require that consent can be given coherently or rationally to a series of policies. ${ }^{\mathrm{i}} \mathrm{I}$ will further assume that consent can be aggregated independently of practical or semi-normative issues of delimitation deciding who is a member of the relevant group - and coordination - enabling or facilitating group discussion.

An alternative strategy for dealing with aggregation of consent is to impose rules for the delimitation of groups, in terms of how severely individuals are affected by a policy. In contrast, I assume that affects on members may be of any degree of severity and come in any distribution. This assumption is warranted by two circumstances. First, from a liberal perspective, any option-restriction must be justified and so there is no rationale for excluding individuals because the effect on them is deemed insufficiently severe. Indeed, for the purposes of this discussion I will assume that any imposition of a cost amounts to a restriction. ${ }^{\text {ii }}$ Second, from a practical perspective, it is normally impossible to delimit groups according to how individuals are affected, other than in the most rudimentary sense, such as where they live or work. At the end of the day, policy makers will most often face situations where some people in a given group consent and some do not. My question is what advice the liberal should give a policy maker in such a situation.

My method is explorative and constructive in the sense that I start from a very simple aggregation rule and work myself towards ever more complex rules in order to incorporate aspects that are shown to be important by argument and by the consideration of a series of scenarios. In the next section I describe the dilemma posed to liberal theory by collective self-regulation and in the third the futility of the literature on paternalism in this area. In the fourth section I propose some aggregation rules based 
on fractions of consenters and non-consenters and their motives. In the fifth section I go on to discuss aggregation rules that consider costs and benefits and the issues they raise. The sixth section concludes.

\section{COLLECTIVE SELF-REGULATION}

I take it for granted that restricting a competent person's options for her good without her consent is paternalistic and therefore illiberal. ${ }^{\text {iii }}$ However, a person may want to have her options restricted, since this may bring great benefits and be an important means of shaping her life. As an individual, I sometimes aim specifically to restrict my own options. I may place the alarm clock some distance from the bed in order to restrict my option of turning it off and going back to sleep (without first standing up). I may promise to meet you at the gym or invest in a gym membership in order to restrict my option of skipping exercise (without cost). I may ask you to stop offering me cigarettes, or to hold on to my car keys and not return them before I sober up, for obvious reasons. In general, I make promises and plans and investments in order to direct my future self by restricting my options. Restricting options is a kind of self-direction or self-regulation that makes use of the world and not only the mind.

Sometimes I am more active in creating situations where my options are restricted, sometimes less. Other people may offer to restrict my options, leaving me to accept or refuse their offers. Gyms offer me memberships, friends offer me to make joint gym plans. When I am more on the offer-taking side, we may most naturally speak of consent. Odysseus asked his sailors to tie him to the mast when they approached the sirens' island. If the sailors rather than Odysseus himself would have been the more informed and proactive, they may have offered to tie him to the mast and he may have consented. While it is sometimes important who takes the initiative, we may speak of consent regardless of whether a person actively creates the situation or passively, but informedly and intentionally, accepts it (cf. Feinberg 1986, chapter 22).

As shown by the examples, other people are often essential in enabling us to restrict our options. Depending on the options, we may need the aid of our relatives, our friends, or colleagues, or our community. Importantly, public policies can set up systems to restrict options. The examples above correspond to various forms of public health policy - prohibition and punishment (reproach for breaking a promise to be at the gym), subsidies (lower cost of exercise after buying gym membership), technical design (friend holding car key), and infrastructure design (alarm clock far from bed). When consented to, these policies may be seen as forms of collective self-regulation.

Public health policy can help groups regulate their primarily self-regarding behaviour, but also their other-regarding behaviour. Such regulation can solve prisoners' dilemmas and other coordination problems. There are many options that, while I would 
prefer that I have them rather than not, I would much prefer that none have them rather than all. Such options may concern direct harm to others, but may also concern the use of common assets. I might like having the option of dumping waste in the city park, but prefer that no one has this option rather than all. As for the prisoners, if they have a chance to restrict their dominating option of confessing, they will each deny and so receive a less severe sentence. Regulation of other-regarding behaviour that does not directly harm others may, when consented to, be seen as another form of collective selfregulation.

Restricting unhealthy and dangerous options will normally promote public health. This may be seen as a value in itself. This article, however, concerns justification by consent. As shown by the examples, restricting options may be an integral part of shaping one's life. Even disregarding the value of health, therefore, public health policy presents liberal theory with a dilemma where the value of enabling people to shape their lives according to their preferences conflicts with the disvalue of restricting people's options without their consent. Though policies can sometimes be adjusted to cover only consenters, this is often impossible or prohibitively expensive.

\section{PATERNALISM AND GROUPS}

In the literature on paternalism and anti-paternalism, many person or group cases are seldom discussed. When they are, the discussion is overly simplistic. Important antipaternalists such as (the young) Richard Arneson (1980), Gerald Dworkin (1983) and Joel Feinberg (1986) adopt the group consent assumption without much discussion. ${ }^{\text {iv }}$ This is surprising considering the tension between this assumption and the antipaternalist core position that benefits to a person do not justify limiting her liberty, for example by restricting her options. While group cases are importantly different from single person cases, the group consent assumption implies that, at least interpersonally, losses in terms of restricted options can be justified by gains in, for example, health.

Arneson, Dworkin and Feinberg take very similar positions on group consent. Their view, we may call it the standard view, is to assume that, when a group is divided among consenters and non-consenters, the rationale behind an option-restricting policy targeting that group is either to benefit the consenters, in which case it is nonpaternalistic, or to benefit the non-consenters, in which case it is paternalistic.

Arneson (1980) discusses group cases in connection with anti-duelling laws. He notes that people may prefer not to be confronted with duelling situations even though, if challenged, they prefer to preserve their honour by accepting, rather than avoid harm. If all agree, prohibiting duelling is an unproblematic case of collective self-regulation. However, as Arneson admits, there will always be some dissenters. Thus - the standard view: Even if some potential duellers are against the policy, 
if it is this pattern of desires [not to be confronted with dueling situations] that generates reasons for forbidding dueling, then the antidueling law (even if it is unfair or unjust) is nonpaternalistic. (Emphasis added, pp. 471-2)

Dworkin (1983) adopts the standard view in a discussion of fluoridation of water, a common public health measure which is typically resisted by a minority:

$[T]$ he restriction on the minority is not motivated by paternalistic considerations, but by the interests of the majority who wish to promote their own welfare. Hence, these are not paternalistic decisions (emphasis added, p. 110).

Feinberg (1986) has some minor issues with Arneson's account but adopts a very similar position:

When most of the people subject to a coercive rule approve of the rule, that is legislated [etc.] for their sakes, and not for the purpose of imposing safety or prudence on the unwilling minority ('against their will'), then the rationale for the rule is not paternalistic. [...] Depending on the collective good involved, the costs and benefits, and the comparative sizes of the majority and minority, the statute may be fair or unfair, wise of unwise, but in either case, it will not be 'paternalistic.' (Emphasis in original, p. 20)

These three accounts are almost identical. If the rationale for an option-restricting policy is to benefit the consenters, then it is not paternalistic. Arneson does not, like Dworkin and Feinberg, explicitly state that the consenters must be in the majority, but he certainly assumes that they are.

The quoted passages are from the 1980s. However, the standard view is alive and well. In a recent article, J.D. Trout (2005) claims that an 'intervention that is based on third-party effects is not paternalistic.' (Emphasis added, p. 412) Trout's example is fluoridation of the local water supply. Given that such a policy is less expensive and more effective than the distribution of fluoride pills and that it is in some people's best interest, Trout concludes that the imposition of this policy on you against your will 'is for their sake and not solely for yours' and so is non-paternalistic. (p. 413) In other words, the policy is non-paternalistic even if some people 'want to defect'. (p. 413).

There are three related and serious problems with the standard view with its focus on the rationale (reason, motive) for a policy. First, it is not clear how the motive of the policy-maker affects the moral status of the policy. We must distinguish between moral evaluation of a policy-maker's decision and moral evaluation of the policy itself. 
This distinction is warranted because we might accept or support a policy because of its effects, or because of the legitimacy of the procedure that produced it, or because it is consented to by those affected, and all this independently of the motives of the policymaker. A policy may be motivated by whatever obscure reason, such as furthering the policy-maker's career or making good on a bet. These motives might affect our moral assessment of the policy-maker's character and our attribution of praise and blame. However, in deciding whether a policy is justified, we are interested not in motives or psychological reasons, but in justificatory reasons. ${ }^{\mathrm{v}}$

Second, while policy-makers might certainly view policy-making as a means to achieving certain pre-defined goals, they arguably should not. They should not act on their motives independently of the preferences of those affected, but rather consider the preferences (and perhaps interests) of all those affected and allow them their due impact on the formulation of policy. The good policy-maker considering whether to enact an option-restricting policy should ask: What is the due impact of the consenters and the non-consenters, respectively? On the standard view, since the rationale of a policy is either to benefit the consenters or to benefit the non-consenters, this question is not even intelligible. The standard view is only applicable to policies for which there is a single, pre-defined rationale. ${ }^{\mathrm{vi}}$

Third, and most saliently, the standard view takes no notice of the fact that nonconsenters have their options restricted against their will. Arneson and Feinberg point out that non-paternalistic polices may be objectionable on grounds of justice or fairness. They do not mention liberty. In the context, calling a policy non-paternalistic and not mentioning other potential conflicts with liberty is to adopt the group consent assumption. It is also to accept that societies with majorities bent on zealous selfregulation may impose strict health regimes on all citizens. It seems that Arneson, Dworkin and Feinberg do not consider the restriction of the options of the minority to be in itself a moral obstacle to enactment of policy once the majority has consented. This is too hasty. As will become clear, the group consent assumption can be specified in a number of different ways, which are more or less liberal, more or less in tune with the spirit of anti-paternalism. Norman Daniels is right to point out that a claim that workplace safety regulation, or any other protective measure, enacted in response to majority will is not paternalistic ignores [...] the libertarian insistence that the autonomy of the minority is a fundamental liberty, a right, not a privilege so easily suspended at majority whim.' (2008, p. 197) Depending on our terminology, such measures may or may not be paternalistic, but regardless of terminology they are problematic from a liberal point of view.

It may seem misguided to look for answers in the paternalism literature when aggregation of consent is more reminiscent of aggregation of votes or preferences and so akin to social choice and democratic theory. However, group consent should not be 
confused with democratic decision making. Majority vote by a legitimate parliament may justify restricting people's options. This, however, is a separate and controversial claim. The liberal would typically hold that policies can be illiberal even if they are sanctioned by a democratic government (or that the government is truly democratic only if it abstains from such policies). The justification provided by consent is more substantial than that possibly provided by democratic decision making (which explains why some theories see consent as the foundation of democratic legitimacy). This is obvious if we look to medical ethics and the common position that treatment is justified only with the individual patient's informed consent (and so could not be sanctioned by democratic decision-making among patients).

In single person cases, consent is generally presumed to fully justify restriction of options. In other words, restricting the options of someone who consents is not to limit her liberty and so there is no prima facie wrong that needs justifying. On a strong interpretation of the group consent assumption, the same is true for group cases - that the group can be treated as if it had collectively consented means that the restriction of the options of its members is in no way morally problematic. This, however, may be too strong. Weaker interpretations are possible. I will not commit to a position on the exact moral impact of group consent but rather investigate when groups can plausibly be said

to consent to a policy, under the assumption that such consent has substantial moral impact, if not enough to completely justify the restriction of options.

\section{AGGREGATION RULES FOR FRACTIONS}

In order to determine when a group can be treated as if it consents to an optionrestricting policy, we clearly need a more fine-tuned theory than what can be found in the paternalism literature, and one focused not so much on the policy-maker as on group members. In this section and the next, I will consider a series of increasingly complex rules for aggregation of individual into group consent. Perhaps the most obvious factor to consider is the fraction of consenters. As noted, Feinberg, Dworkin and Arneson assume, explicitly or implicitly, that a group consents only if a majority of its members consent. However, we must remember that group consent is not a matter of democratic decision-making but of more substantial moral justification. The issue is one of balancing liberal interests in self-regulation against liberal interests in non-restriction of options. The more libertarian our liberalism, the higher a fraction should be demanded. Consider, therefore, this simple rule:

The fraction consent rule: A group consents to an option-restricting policy if a large enough fraction of group members consent to the policy. 
'Large enough' can be specified once and for all or can be allowed to vary with context. One problem with this rule arises from the possibility of altruistic consent. ${ }^{\text {vii }}$ Consider the following scenario:

Altruism. A group consists of two types of people - As and Bs. There is a policy that can be applied to the whole group or not at all. The policy restricts an unhealthy option (that the As hardly ever choose but that the Bs choose frequently). The Bs do not consent to the policy because they think it goes against their best interest. The As consent to the policy because they think it is in the best interest of the Bs.

From a liberal perspective, it would seem that in consenting, the As join rank with the paternalistic policy-maker in forcing a restriction on the Bs against their will. It seems counter to the spirit of justification by consent that the altruistic consent of the As should justify restricting the options of the Bs. Furthermore, it seems irrelevant what is the exact number or fraction of As. That a million rather than a thousand altruistic consenters accept a restriction that they have little or no personal interest in, for the sake of a few non-consenters, does not make it more reasonable to treat the group as if it had collectively consented.

This is not to say that altruistic consent counts for nothing. It is arguably less morally problematic to restrict the options of altruistic consenters than to restrict the options of non-consenters. In fact, this is exactly what I will soon argue. However, the point of collective self-regulation, from a liberal perspective, is that people should be free to restrict their own options in order to shape their own lives, not that they should be free to limit the freedom of others for their good against their will.

Though Arneson, Dworkin and Feinberg do not explicitly consider the motives of consenters, their insistence that a non-paternalistic policy be enacted 'for the sake of (etc.) the majority suggests excluding justification based on altruistic consent. Here is a rule that does:

The fraction self-interested consent rule: A group consents to an option-restricting policy if a large enough fraction of group members consent to the policy out of selfinterest.

Altruistic consent gives rise to another kind of problem for this rule. Excluding altruists from the fraction that counts towards group consent means including them in the remainder. In other words, every extra altruist counts against consent. With a constant number of self-interested consenters, and a constant number of non-consenters, 
increasing the number of altruistic consenters will change the status of the group from consenting to non-consenting, and vice versa for decreasing numbers of altruists.

Moreover, every extra altruist counts against consent to the same extent as every extra non-consenter. I propose that this position entails an unacceptable disregard for the disvalue of restricting a person's options against her will. The rule is inconsistent with the strong intuition that it is less morally problematic to restrict the options of altruistic consenters, who do after all consent, than to restrict the options of nonconsenters against their will. To see this more clearly, assume that the required fraction is $70 \%$ and consider this scenario:

Gambling. A local prohibition of gambling restricts the options of a group consisting of 24 members - 20 who are addicted gamblers and who consent out of self-interest, two who would hardly ever gamble anyway and who consent for altruistic reasons, and two who love to gamble and who therefore do not consent.

According to the fraction self-interested consent rule, the group consents to this policy $(83 \%$ self-interested consenters). Now if the community grows with five people who would hardly ever gamble anyway and who therefore accept the prohibition for altruistic reasons, the group no longer consents to the policy (69\% self-interested consenters). This might already seem counter-intuitive - why would the liberty of these new members to gamble be so important, given that they are not that interested in gambling and that they consent to the prohibition? ${ }^{\text {viii }}$ What is more disturbing, however, is that if the community grows with four people who love to gamble and so do not accept the prohibition, the group still consents to the policy ( $71 \%$ self-interested consenters). While five additional altruistic consenters would end group consent, four additional nonconsenters would not. Those of us who find this counter-intuitive should prefer this rule:

The fraction self-interested consent vs. non-consent rule: A group consents to an option-restricting policy if the fraction of members that consent to the policy out of selfinterest is large enough compared to the fraction that do not consent.

Another form of altruism gives rise to similar complications. Group members might feel that our typical altruistic consenters, as well as self-interested consenters, trade off their freedom too lightly. They may therefore refuse to consent for liberty-preserving altruistic reasons, possibly against their own self-interest. The issues raised by this possibility are analogous to those of standard health-promoting altruism. In response, we may propose this modified rule: 
The fraction self-interested consent vs. self-interested non-consent rule: A group consents to an option-restricting policy if the fraction of members that consent to the policy out of self-interest is large enough compared to the fraction that self-interestedly do not consent.

This rule takes altruists out of the equation altogether (along with group members who consent or not for yet other reasons, or are indifferent). Altruists neither contribute to nor subtract from group consent. This may be reasonable. However, it implies, for example, that a group consents if it consists of a million altruistic consenters, two selfinterested consenters, and one self-interested non-consenter, while it does not consent if it consists of a million altruistic consenters, one self-interested consenter, and two selfinterested non-consenters. Depending on one's convictions or intuitions, this might seem to either undervalue the free options of altruists, or to undervalue the altruists' free consent. To satisfy such intuitions, more complex rules could be designed that let altruistic consenters contribute to group consent, only discounted by some factor less than one, or that let altruistic consenters count against group consent, similarly discounted. In the same discounted fashion, altruistic non-consenters could count against group consent.

There are further complications. Just like policy-makers, consenters may have more than one motive. People may consent to a policy that restricts their options partly because they see that this will promote their health, and partly because they think that it will promote the health of others. Indeed, such motives are typical. In order to accommodate mixed rationales for consent, we could distribute the consent or nonconsent of each member over the categories of the altruistic and the self-interested. With this scheme in place, we could further allow that preferences be distributed over both consent and non-consent, in order to accommodate hesitation and people who are conflicted concerning altruism and self-interest. Alternatively, and more rigidly, we could attribute to each member both a self-interested preference and an altruistic preference. These two kinds of preferences may then count equally or differently in the balancing of consent against non-consent. All this means that there are several alternative ways to accommodate altruism. Here are two rules that allow altruistic non-consent to count against group consent and altruistic consent to count either for (first rule) or against (second rule) group consent, though discounted, and that employ the former, less rigid strategy for accommodating mixed motives:

The fraction self-interested plus discounted altruistic consent vs. self-interested plus discounted altruistic non-consent rule: A group consents to an optionrestricting policy if the fraction of self-interested consents plus the discounted fraction 
of altruistic consents is large enough compared to the fraction of self-interested nonconsents plus the discounted fraction of altruistic non-consents.

\section{The fraction self-interested consent vs. self-interested plus discounted altruistic} consent and non-consent rule: A group consents to an option-restricting policy if the fraction of self-interested consents is large enough compared to the fraction of selfinterested non-consents plus the discounted fraction of altruistic consents and nonconsents.

Consents and non-consents should here be understood not as individual consents but as distributed consents as just explained. This is as far as I will go with aggregation rules based on numbers or fractions of consenters and non-consenters, with different motives. We may conclude that in order to accommodate varied but common preferences, such rules must be rather complex. In the following section, I will argue that aggregation rules must consider not only fractions and motives, but also costs and benefits.

\section{AGGREGATION RULES FOR COSTS AND BENEFITS}

Aggregation rules based on fractions do not consider the cost or the benefits to different members. From a liberal perspective, this may be considered a virtue. However, sometimes the benefits for each consenter are great and the cost to each non-consenter trivial. Sometimes it is the other way around. I propose that once we accept the group consent assumption and so allow the interests of some members to override the interests of others, it is unreasonable not to consider the relative strength of these interests. ${ }^{\text {ix }}$

Consider this scenario:

Spartan Regime. A group of warriors train hard in the mornings and evenings but tend to spend the warm afternoons lying around in the shady courtyard outside the barracks. A decree will prohibit loitering in the courtyards, in order to promote training. $81 \%$ of the warriors are good Spartans and though they would not train more but rather spend afternoons walking the fields, they appreciate the spirit of the decree. When the captain asks them they say they would welcome the decree. The remaining 19\%, however, are not so good Spartans. They consider it a great honour to be warriors, but they find the training very burdensome. In fact, they could not stand it were it not for the relaxed afternoons in the courtyard, when they can share their troubles and give each other support. The decree would destroy the fragile social context that has evolved around the courtyard. When the 
captain asks them, therefore, they say they would not welcome the decree, for these reasons.

Assume that the good Spartans would appreciate the spirit of the decree in the sense that they would like being regulated by it themselves, not that they would want the not so good Spartans to stop loitering. This allows me to put altruism to one side for the moment. According to the fraction self-interested consent vs. self-interested non-consent rule with an $80 \%$ requirement, the group consents to the decree. I propose that this is unreasonable. There are of course several senses in which the group welcomes the decree, for example the sense that the majority welcomes it. However, in the context of consent, this is not a relevant sense. When the general asks the captain how the warriors feel about the proposed decree, the captain should not say that they welcome it. The option-restricting effects on the non-consenting minority are not balanced out by the consent of the qualified majority. We are not warranted to treat the group as if it had collectively consented. This is so because the trivial (or non-existing) benefits to the majority are too small compared to the great costs to the minority.

Now consider this contrasting scenario:

Meanwhile in Athens. A group of warriors train hard in the mornings and evenings and tend to spend the warm afternoons walking the fields. A decree will command the construction of a shady courtyard outside the barracks, in order to promote socializing and culture. The courtyard will make it more difficult to get to the fields. $81 \%$ of the warriors are good Athenians that are very proud to be warriors but are on the brink of despair because they so miss the cultured discussions of the civilian lifestyle. The proposed courtyard would mean the world to them and this is what they tell the captain when she asks. The remaining 19\%, however, are immigrants from Sparta. They would not use the courtyard anyway and though they would not mind the longer path to the fields they do not appreciate the spirit of the decree, and so when the captain asks they say they would not welcome it.

This group may perhaps be said to consent to the decree, in accordance with the fraction selfinterested consent vs. self-interested non-consent rule with an $80 \%$ requirement. When the Athenian general asks his captain how the warriors feel about the proposed decree, the captain could without fault say that they welcome it. If there is no time to describe the situation in further detail, that is indeed what she should say. Though the group is divided, it may on the whole be treated as if it had collectively consented. This is so because the benefits to the majority are so great compared to the trivial (or non-existing) costs to the minority. 
It could be argued that it is simply misleading to talk of group consent in these cases. However, the issue is not whether group consent is a coherent notion when a group is divided. We are discussing aggregation of individual into group consent under the assumption that it is meaningful to do so under some circumstances, for example when a policy-maker, or general, must decide one way or other and perhaps wants to consider the consequences for the group in terms of enabling self-regulation and avoiding non-consented to restriction of options. Spartan Regime is not so unlike the prohibition of smoking in pubs, with the significant difference that smoking directly harms third parties. The question of balancing the consent of the good Spartans against the non-consent of the not so good Spartans is analogous to the question of how to balance the (let us assume) consent of the light smoking majority who wants to quit against the non-consent of the heavy smoking minority who have their whole lifestyle structured around smoking in the pub and do not want to quit. Meanwhile in Athens is analogous to common public health measures such as product safety regulation, sin taxes and subsidies, where these are urgently welcomed by a qualified majority but opposed as a matter of principle by a minority of libertarians.

The fraction self-interested consent vs. self-interested non-consent rule with an 80\% requirement implies that both the Spartans and the Athenians consent. The requirement could of course be any fraction and the scenarios reformulated accordingly. What is problematic is that the rule does not distinguish between the cases. Another way to bring out this problem is to lower the fraction of consenters in Athens to $79 \%$. Now this group does not consent, while the Spartan group does. This is unreasonable. I conclude that rules for aggregating individual into group consent must pay some attention to costs and benefits.

There are as far as I can see two ways to introduce such consideration. One is to discard fractions and focus entirely on costs and benefits. Here is a rule that does (and excludes altruists):

The cost-benefit self-interested consent vs. self-interested non-consent rule: A group consents to an option-restricting policy if the benefits to those members who consent to the policy out of self-interest are greater than the costs to those members who self-interestedly do not consent.

Spartan Regime and Meanwhile in Athens show that costs and benefits must be considered, not that they must be decisive. A more conservative way to introduce considerations of costs and benefits is to keep the focus on numbers or fractions and let them be adjusted by the size of costs and benefits: 
The fraction cost-benefit self-interested consent vs. self-interested non-consent rule: A group consents to an option-restricting policy if the benefit-adjusted number of members that consent to the policy out of self-interest is large enough compared to the cost-adjusted number of members that self-interestedly do not consent

Different versions are possible. The adjustment according to cost and benefit need not be strictly proportional. ${ }^{\mathrm{x}}$ The adjustment can be made for each individual or by median or mean for the respective subgroup.

Talk of costs and benefits does not imply a commitment to some particular theory of the good. The scenarios show that, in some sense, the costs of the optionrestricting policy in Sparta are larger than the benefits, while in Athens the benefits of the option-restricting policy are larger than the costs. In this sense there are costs and benefits of policy alternatives and to this extent they are comparable. I will leave it an open question whether these costs and benefits are dependent on the objective value of health and liberty, or whether they are rather dependent on subjective preference. I will also leave it an open question to what extent these kinds of costs and benefits are comparable in general. As a matter of practical necessity, they must often be compared when making policy choices, or at least policy choices must be made as if they had been compared. $^{\text {xi }}$

Whether we should prefer the cost-benefit self-interested consent vs. self-interested nonconsent rule or the fraction cost-benefit self-interested consent vs. self-interested non-consent rule depends in large part on how we deal with two main issues that face both rules - should costs and benefits be understood as gross or net, and (how) should the rules be modified to consider the cost and/or benefits to (part) altruists. I will deal with these issues each in turn. I should state at the outset that I will not take a definite stand on these issues, nor on which of the rules should be preferred.

\section{Net or gross}

We have been concerned exclusively with benefits to consenters and costs to nonconsenters. However, a policy that we self-interestedly consent to because of its benefits need not be free of costs. I may welcome a prohibition on gambling while I recognize that it will prevent not only my excessive Friday night gambling sprees (the gross benefit), but also my innocent and pleasant Sunday afternoon poker. In considering the benefit to me of stopping the gambling sprees, should we subtract the cost of stopping the Sunday poker (to get the net benefit)? I propose that we have a basic intuition in favour of net cost or benefit. Assume that the effect for A is a great benefit and an almost as great cost, while the effect for $B$ is a small benefit and an even smaller cost. Assume that the net benefit is equally large for A and B. It seems arbitrary and uncalled for that the effect on A should count for more than the effect on B. 
However, net cost or benefit may be thought problematic in that it implies that the cost to self-interested non-consenters can be negative - i.e. they may benefit from a policy they do not consent to. For example, people who do not consent to fluoridation of tap water may benefit more from improved dental health than they lose in restricted options, though they themselves do not think so. Indeed, (paternalistically inclined) policy-makers will often believe that this is the case. Conversely, the net benefit to selfinterested consenters can be negative - i.e. they may not benefit from a policy they consent to, but rather face a net cost. For example, people who consent to subsidies for gym memberships in order to make themselves exercise may fail to do so while still paying for the subsidy. Whether or not costs or benefits are in fact negative in a certain case will depend on empirical circumstances (and on what is the correct theory of the value of health and of the disvalue of restriction of options).

Under the cost-benefit self-interested consent vs. self-interested non-consent rule, net cost or benefit imply further that it does not matter whether or not members consent. This is so because we count both the costs and the benefits to both consenters and non-consenters and all these effects count equally. The rule can therefore be simplified:

The cost-benefit self-interested rule: A group consents to an option-restricting policy if it entails a net benefit to its self-interested members.

If we take the further step of counting also costs and benefits to altruists, as I will later argue we should if we settle for net cost or benefit, the rule reduces to standard consequentialist cost-benefit analysis:

The cost-benefit rule: A group consents to an option-restricting policy if it entails a net benefit to group members.

These rules may be reasonable. If we accept one of them, consent can still have an indirect effect in that the cost of having ones options restricted is greater, ceteris paribus, if one does not consent to such restriction. It is noteworthy that aggregation of individual into group consent will take us to cost-benefit analysis under these assumptions.

The possibility of negative costs and benefits is excluded if we opt for gross rather than net (gross costs and benefits to different members are of course aggregated into a net for the group - we must distinguish between the individual net and the group net). The lowest gross cost or benefit is simply zero, which in the case of the fraction costbenefit self-interested consent $v$ s. self-interested non-consent rule may be taken to leave the number of (non-)consenters intact but without positive adjustment. More generally, opting for gross costs and benefits does not allow that benefits that are not consented to or costs 
that are consented to count for or against group consent. In other words, while effects on individual interests can enhance the impact of an individual's (non-)consent, it cannot diminish it. This may be a means of preserving a strong form of respect for individual choice even while allowing costs and benefits some impact - an impact that is sufficient to explain our intuitions in Spartan Regime and Meanwhile in Athens, where there are no or only trivial benefits to non-consenters and costs to consenters.

However, these arguments for gross do not undermine our basic intuition in favour of net cost or benefit. Furthermore, this intuition can be strengthened by considering scenarios where the benefits to non-consenters are great, or where the costs to consenters are great, and where these great costs and benefits are recognized as such by the (non-)consenters themselves. Consider:

Smoking. A public policy targeting a group of heavy smokers will levy high taxes on cigarettes (and use the surplus elsewhere). A majority consent to the policy because they know it will help them to marginally decrease their smoking. However, they recognize that the financial cost to them will be substantial. A minority do not consent to the policy because they know that it will not help them decrease their smoking and they recognize the financial cost. (If you think that the majority is being irrational to opt for a small benefit at substantial cost, assume that they think they deserve to be punished for their imprudent and morally irresponsible lifestyle.)

Smoking 2. Like Smoking but the consenters are only light smokers and so the cost to them is smaller. Nonetheless, the health benefits from a marginal decrease in smoking will be equal to those of the consenters in Smoking.

Smoking 3. Like Smoking but the non-consenters know that the policy will help them decrease their smoking substantially. (They still do not consent because they are against being taxed.)

If we count only gross benefits to consenters and gross costs to non-consenters, the three scenarios are equivalent. However, the net costs and benefits are substantially different. If the fraction of consenters required for the policy to be justified in each scenario varies, this indicates that we should understand costs and benefits as net.

We must not be fooled by possible intuitions to the effect that the lower cost in Smoking and the higher benefit in Smoking 2 should have some impact on the justification of policy. The question is which costs and benefits should have an impact on justification by group consent. Remember that the basic rationale for the group consent assumption is that consenters should be free to shape their lives according to their 
wishes. We might ask, therefore, whether it is more important for the consenters in Smoking 2 to restrict their options than for the consenters in Smoking. I propose that it is.

As argued in the introduction, wanted and beneficial restrictions are important in shaping our lives. I propose that restrictions that are more wanted and more beneficial are more important. When I consider what is beneficial to myself in shaping my life I think in terms of net - I include the entailed costs of beneficial and wanted outcomes. If I decide to get married or to pursue a career in philosophy or to run for office, I consider both pros and cons, both costs and benefits. A rule that protects my life shaping and that of my fellow group members should distinguish between great benefits at low cost and great benefits at great cost.

We may then ask whether it is less important for the non-consenters in Smoking 3 to avoid restriction than for the non-consenters in Smoking. Again, I propose that it is, for similar reasons. Unwanted and non-beneficial restrictions are important to avoid. Restrictions that are more wanted (less unwanted) and more beneficial are less important to avoid. A rule that protects my options and those of my fellow group members should distinguish between great costs for no benefit and great costs for substantial benefit.

In sum, I find the case for net cost or benefit stronger than the case for gross. However, there are good arguments on both sides and so I am happy to leave the matter undecided.

\section{Altruism}

As noted, the possibility of altruistic consent requires that we specify the motives of (non-)consenters. The cost-benefit rules I have formulated so far in this section exclude altruistic (non-)consent. This avoids the possibility that altruistic consenters indirectly force benefits on non-consenters against their will or that altruistic non-consenters indirectly prevent consenters from shaping their lives according to their preferences. However, as noted, it may be too drastic to simply disregard altruistic (non-)consent. The fraction and number based rules can all be modified to grant altruism full or discounted impact. This is true also for the fraction cost-benefit self-interested consent vs. selfinterested non-consent rule. In the case of the cost-benefit self-interested consent vs. self-interested nonconsent rule, fractions do not matter and so the question is simply whether costs and benefits to altruists count and if so whether in full or discounted.

Consider this scenario:

Gambling 2. A local prohibition of gambling restricts the options of a group of addicted gamblers. The members can be divided into six subgroups. The first subgroup knows the policy will help them out of their addiction - a great net benefit - and consent for that reason. The second subgroup knows that the policy will destroy their most cherished hobby - a great net cost - and for that reason do 
not consent. The third subgroup knows the policy will help them out of their addiction, but have no concern for themselves. On the other hand, they also know that the policy will help the first (and the fifth) subgroup out of their addiction and consent for that reason. The fourth subgroup knows the policy will destroy their most cherished hobby, but have no concern for themselves. They also know, however, that the policy will destroy the cherished hobby of the second (and the sixth) subgroup, and for that reason they do not consent. The fifth subgroup, like the third, knows the policy will help them out of their addiction, but have no concern for themselves. Unlike the third subgroup, they do not consent, in order to protect the cherished hobby of the second (and the sixth) subgroup. The sixth subgroup, like the fourth, knows the policy will destroy their most cherished hobby, but have no concern for themselves. They consent, however, in order to help the first (and the fifth) subgroup out of their addiction.

Which of these costs and benefits should have an impact on group consent? The four altruist subgroups can be divided along two dimensions - whether they stand to win or lose from the enactment of the policy, and whether they sympathize with those who stand to win or with those who stand to lose. Their sympathies in turn determine whether they consent or not. However, I propose that the singularly most relevant aspect, cutting across the two dimensions, is whether or not the (non-)consents of the altruists are in conflict with their own interests (this aspect could have been exemplified with two altruistic subgroups - all four are included for comprehensiveness, illustrating, as noted above, that there may be altruists both among consenters and non-consenters).

We are arguably most likely to accept as relevant the costs and benefits to those altruists (the third and fourth subgroup) who consent or not consistently with their own interest. Their noble or self-denying character should not count against them and there is no conflict between what they prefer and what is in their interest. We are probably more reluctant to accept as relevant the costs and benefits to those altruists (the fifth and sixth subgroup) who consent or not in conflict with their own interest. To allow that these costs and benefits affect group consent is to allow individual interests to diminish or count against individual consent.

The issue is essentially the same as whether or not costs to self-interested consenters and benefits to self-interested non-consenters should ever lessen the impact of their (non-)consent. As noted, that they should not is a good argument for understanding costs and benefits as gross rather than net. Consistency therefore requires that we either settle for gross costs and benefits and disregard costs and benefits to altruists that consent or not in conflict with their own interest, or that we settle for net cost or benefit and consider the cost or benefit to all altruists. It is this reasoning that implies that the self-interested cost-benefit rule reduces to the cost-benefit rule, as indicated above. 
After deciding which types of altruist cost and benefits should count in aggregating group consent, the next pressing matter is whether these costs and benefits should count as equal to those to self-interested members or whether their impact should rather be adjusted by some factor. Many possibilities suggest themselves. However, this is as far as I will go with this issue.

In sum, there are strong reasons to include at least some altruist (non-)consenters in the numbers under the fraction cost-benefit self-interested consent vs. self-interested non-consent rule, and among the 'containers' of costs and benefits under the cost-benefit self-interested consent vs. self-interested non-consent rule. If we should include altruists that consent or not in conflict with their own interest, and whether or not (different kinds of) altruists should count equally with self-interested members, these questions I leave undecided.

\section{CONCLUSION}

Option-restricting public health policies that are welcomed by some of those affected but not by others raise intriguing problems for liberal political theory. One approach to these problems is to investigate under what conditions groups that are divided can be treated as if they had collectively consented. This issue has been too hastily dismissed by several anti-paternalists, even though the core values underlying anti-paternalism are clearly relevant to how it should be handled. Once we recognize the need to consider costs and benefits, we must ask whether they can count against individual consent. In the spirit of anti-paternalism, we should perhaps say no. This entails saying no to negative costs and benefits, and no to discounting altruistic consent because it is in conflict with self-interest. On the other hand, once the importance of costs and benefits is acknowledged, strong intuitions drive us to consider not only gross, but net cost or benefit. If we do, consenters who stand to benefit more will count for more than those who benefit less, non-consenters who stand to loose more will count for more than other non-consenters, and altruistic consenters that consent or not in conflict with their own interests will count for less than those who consent or not consistently with their own interest. It is not obvious how we should react to these results. They should therefore be investigated in further scenarios and preferably also in application to real cases.

Regardless of how these issues are finally resolved, aggregation rules for individual into group consent must consider both costs and benefits to group members, and their motives for (non-)consent. Under net cost and benefit, the cost-benefit selfinterested consent vs. self-interested non-consent rule reduces rather straightforwardly to the costbenefit rule, saying that a group consents if its members can on the whole expect a net benefit. Coupled with an understanding of cost and benefit as gross, however, this rule offers an interesting compromise between outright consequentialism and more 
principled liberalism. The fraction cost-benefit self-interested consent vs. self-interested non-consent rule offers another such compromise and can be combined with either gross or net costs and benefits. This rule is very general and can be specified in any number of ways. If the general approach has some merit, more detailed rules should therefore be formulated. Both rules should be adjusted to allow altruistic non-consenters who do not benefit to count against consent. Both rules may or may not be adjusted to allow other altruists to have an impact on group consent.

Stepping back from the details, we may conclude that a theory of justification of option-restricting policies by group consent is possible but will necessarily be quite complex. These complexities, and the introduction of costs and benefits, may tempt the liberal to reject the group consent assumption and claim in a Nozickian manner that restricting the options of competent people against their will is simply impermissible, except when doing so is the only way to avoid catastrophe (Nozick 1974). However, depending of course on how loosely catastrophe is defined, the price would be great in terms of limits on how individuals can use the power of collective self-regulation to shape their own lives. The opposite reaction is perhaps more sensible - to reject group consent as a source of justification for public health policy and look to other sources.

i I will therefore not consider the growing literature on preference aggregation and, more recently, judgement aggregation, which deals predominately with such issues. Aggregation of consent is distinct from aggregation of preferences, judgement or welfare. Aggregation rules may always be vulnerable to Condorcet's paradox (the voting paradox) and similar paradoxes. Such vulnerability does not imply that aggregation has no moral impact. Majority vote may make a government legitimate, even if there is a possible majority among voters that would prefer another government over the present one and another majority that would prefer a third one over the second one and yet another majority that would prefer the present one over the third one. Likewise, group consent may justify option-restricting policies, even in the face of similar cyclicality.

ii What counts as an imposition of a cost is always relative to a baseline. My investigation must therefore be understood against the background of some general theory of justice which defines such a baseline.

iii Provided that she is sufficiently capable and informed and so her choices sufficiently voluntary.

iv I count Dworkin as an anti-paternalist because he holds that paternalism is prima facie wrong, even though he is happy to make exceptions. Regardless of the appropriateness of this label, his account of paternalism and group cases is typical of liberal philosophers.

v Arneson's 'generates reasons' seems at first to refer to justificationary reasons, but he immediately goes on to sort cases according to 'the motivation of the lawmakers' (p. 472).

vi Admittedly, claims that option-restricting policies are paternalistic only if their rationale is to benefit non-consenters could be reinterpreted, in the spirit of Husak (2003) and Grill (2007), to mean that it is paternalistic to allow that benefits to non-consenters count in favour of option-restricting policies. However, if anti-paternalism is limited to excluding such reasons, it has nothing to say about the dilemma policy-makers face when they must choose whether to enable people to shape their lives according to their wishes or to avoid restricting people's options without their consent.

vii Similar problems arise for consent based on any kind of external preference (a preference regarding the outcome for others). The case of altruism (directed at other group members) is especially interesting because it is common and apparently benevolent and legitimate.

viii It may be argued that these non-gamblers should not count as members of the group. However, as noted in the introduction, their options are still restricted and it is practically very difficult to delimit groups according to individual interest. It is of course equally difficult to ascertain individual interest for 
the purpose of aggregating consent. However, consent aggregation is an ideal to be approximated, an abstract moral rule that must be adjusted in the face of practical constraints. If we understand group delimitation the same way, and if we allow that delimitation is not digital but come in degrees, then what I say about consent aggregation can be translated into delimitation talk, and the two strategies are in that sense equivalent.

ix Similar intuitions seem to have led Brighouse and Fleurbaey (2008) to argue for power in proportion to stakes in any decision-making process. Their discussion is more general and placed in the context of democratic theory. They dismiss the problem of altruism on grounds I fail to see.

$\mathrm{x}$ This opens the door to mimicking various theories of distributive justice. For example, prioritarian versions are possible. However, we must remember that what we are investigating is aggregation of consent and not considerations of justice, which may in themselves of course justify restricting options, or define what is a restriction in the first place.

xi Those who are still wary of talk of costs and benefits might prefer to formulate aggregation rules in terms of reasons. That some restrictions of options are more severe than others and that some benefits are larger than others might be taken to imply that some reasons against restricting options are stronger than others and that some reasons for creating benefits are stronger than others. Switching terminology to reason talk may seem to automatically give us the common currency of strength with which to compare different considerations. In fact, however, this gain is superficial, since we still have to determine the function to the strength of reasons from the severity of restrictions of options and from the size of benefits, respectively. I will stay with the language of costs and benefits rather than that of reasons, with the assumption that everything I say can be straightforwardly translated into reason talk.

\section{References}

Arneson, R. (1980). 'Mill versus Paternalism'. Ethics 90: 470-489.

Brighouse, H., and Fleurbaey, M. (2008). 'Democracy and Proportionality' Journal of Political Philosophy Advance Access published July 10, 2008, doi: 10.1111/j.14679760.2008.00316.x.

Daniels, N. (2008). Just Health: Meeting Health Needs Fairly. Cambridge: Cambridge University Press.

Dworkin, G. (1983). 'Some Second Thoughts'. In Rolf Sartorius (ed.), Paternalism. Minneapolis: University of Minnesota Press, pp. 105-11.

Feinberg, J. (1986). Harm to Self. Oxford: Oxford University Press.

Grill, K. (2007). 'The Normative Core of Paternalism'. Res Publica 13: 441-458.

Husak, D. (2003). 'Legal Paternalism'. In The Oxford Handbook of Practical Ethics. Oxford: Oxford University Press.

Nozick, R. (1974). Anarchy, State, and Utopia. Malden MA: Basic Books.

Trout, J.D. (2005). 'Paternalism and Cognitive Bias'. Law and Philosophy 24: 393-434. 